\title{
HUMOR, IRONÍA Y SUBVERSIÓN EN LA CALLE, JINETE Y YO
}

\author{
José Ángel Vargas Vargas
}

\begin{abstract}
RESUMEN
En esta ponencia se analiza la novela La calle, jinete y yo (1975) de Hernán Elizondo Arce (1921) desde una perspectiva ideológica, con el fin de determinar el modo como el escritor enuncia y subvierte las jerarquías asociadas a códigos religiosos, familiares y políticos. Se parte de una caracterización del contexto en el que se produce la obra y en un segundo momento se determina la función que cumplen el humor y la ironía, como recursos retóricos que desestabilizan diversas instancias del poder. Estos mecanismos le permiten al autor mostrar una insatisfacción ante el autoritarismo, la violencia y la corrupción, rasgos característicos del icono de una sociedad mediocre y conformista, edificado por la obra, de manera que ésta se constituye en un significativo antecedente de la narrativa producida en las siguientes décadas, cuyo énfasis está centrado en el tema del desencanto.

Palabras clave: humor, ironía, literatura, subversión, Hernán Elizondo.
\end{abstract}

\begin{abstract}
In this work "La Calle, Jinete y yo" (1975) by Hernán Elizondo Arce (1921) is analyzed from an ideologic point of view, to determine the way the writer states and overthrows the hierarchies related to religious, familiar, and politic codes. Firstly, it starts with a characterization of the contexts in which the novel is created and secondly, the function of the humor and irony as rethorical resources that unstable different power instances is determined. These mechanisms let the authoritarianism, violence and the corruption. These are characteristic features of the icon from a conventional and mediocre society, built by the novel in a way that constitudes an antecedent meaning of the narrative from the next decades, whose emphasis is based in the disenchant subject.
\end{abstract}

Key words: humour, irony, literature, subversion, Hernán Elizondo.

\section{Introducción}

La narrativa costarricense de los años setenta se caracteriza principalmente por introducir dos cambios en relación con la producida en las décadas anteriores: por un lado, busca la superación del realismo y, por el otro, ficcionaliza el espacio urbano y la problemática que este encierra.

José Ángel Vargas Vargas. Doctor en Literatura, Profesor Catedrático, Universidad de Costa Rica. San Pedro, San José, Costa Rica.

Correo electrónico: vyvosa@ racsa.co.cr 
La superación del realismo no implica prescindir de la realidad referencial, porque los contextos en que se desenvuelven los escritores están conformados por múltiples particularidades (sociales, culturales, ideológicas); se trata, más bien, de una nueva postura epistemológica en la que se emplean códigos estéticos que permiten asediar diversos problemas sociopolíticos, para crear imágenes del entorno costarricense. Este cambio obedece a una liberación de todo mimetismo estático, posibilitando con ello que la obra se convierta en "un campo de juegos verbales para visualizar modelos de la realidad situados más allá de los modos racionalistas de percibir la identidad del ser, del espacio y del tiempo" (Arias 1990: 16) ${ }^{1}$, por lo que la reproducción de las condiciones de vida de la sociedad y la denuncia política han dejado de ser una finalidad en sí mismas. De esta forma, la realidad es sometida al tamiz de las reglas del discurso literario y representada de un modo dialéctico, con estructuras narrativas innovadoras y complejas.

La incorporación del espacio urbano como motivo literario se justifica en la transformación que está experimentando el país, pues los temas vinculados con la sociedad rural (el paisaje, la naturaleza, la relación obrero/patrono, las costumbres locales) han perdido su protagonismo y en su lugar surgen otros como los cinturones de pobreza, la burocracia y la incipiente modernización concentrada en los principales núcleos de población. Este cambio tiene su antecedente más claro, aunque no definitivo, en la obra de Yolanda Oreamuno y se aprecia ampliamente en las obras de Alfonso Chase (1945), Carmen Naranjo (1930) y Hernán Elizondo Arce (1921).

Mediante la superación del realismo y la incorporación del espacio urbano, los narradores expresan su compromiso social e ideológico con recursos estéticos diferentes a los utilizados por la llamada Generación del 40, donde se presentó una fuerte denuncia de la explotación social. A la vez, estos autores se preocuparon por una expresión más elaborada de la realidad, recurriendo a las formas retóricas más apropiadas como el diálogo, la ironía, el sarcasmo, el humor, con lo que contribuyeron a la aparición de un lirismo justificado en el énfasis que acentuaron en el plano de la enunciación. Este artículo pretende enfocar la obra $L a$ calle, jinete y yo desde una perspectiva crítica en la que se determinan las claves poéticas empleadas por su autor, el carácter ideológico y subversivo de la obra y la construcción del icono de una sociedad mediocre y conformista.

\section{Preocupación existencial y denuncia ideológica}

Escrita entre 1965 y 1966, La calle, jinete y yo constituye una obra que recoge las preocupaciones sociales y existenciales de su autor planteadas en Memorias de un pobre diablo (1964) y anuncia el mundo abrumador y oscuro de La ciudad y la sombra (1971). La obra se sitúa en un doble conflicto: por una parte, el hombre con su existencia, en el que es muy relevante la tensión entre la vida y la muerte, la angustia y el destino, la soledad y la solidaridad, y, por la otra, el ser humano con un medio caracterizado por la irracionalidad y por la violencia.

En esta obra, el lector entra en contacto con el protagonista, un individuo que aparece vinculado a distintas personas, tipos sociales e instituciones, éstas últimas emparentadas con lo que Althusser ha denominado aparatos ideológicos del estado: la familia, la religión y la escuela, sin dejar de lanzar el dardo en múltiples ocasiones contra el poder político, como 
principal generador de conflicto y diferencia. Además, el personaje con insistencia reitera su insatisfacción, no solo con las diversas jerarquías que lo condicionan, sino con la vida y con Dios, pues se encuentra solo y abandonado, no viviendo sino vegetando, imbuido de una filosofía existencialista en la línea de Jean Paul Sartre, como se aprecia en diferentes momentos críticos que atraviesa el protagonista y en la muerte de Jinete, su entrañable amigo:

\author{
No era mi culpa que al nacer se me hubiese metido en el cuerpo un alma de suicida tirada hacia la inercia. \\ ¿Luchar? \\ ¿Para qué? \\ ¿No había luchado con ardor en mis primeros años y el destino había convertido mis ideales en un despo- \\ jo inservible, en un juguete destrozado como el papalote de Santiago? \\ Me había adaptado a la vida, Jinete, desde antes de que tú llegaras. De aquel cristianismo puro de mi niñez \\ ya había perdido la fe y sólo me quedaba el sedimento de la conformidad ante el dolor. \\ Por eso no vivía, vegetaba ${ }^{2}$. \\ Nacer...Morir... \\ Y para qué el advenimiento de la aurora si se llega a la noche del ocaso? \\ Empezamos a morir cuando nacemos o empezamos a nacer cuando morimos? No. No quiero pensar, Jinete. \\ No quiero reclinar las sienes sudorosas sobre el muro de las sombras de las interrogaciones (p. 113).
}

A partir de su existencia múltiple y compleja, y como producto de su relación con Jinete, un perro en el que encuentra la más absoluta identificación, sea para compartir sus insignificantes triunfos, sea para evidenciar su concepción de la realidad, el narrador edifica un icono de la realidad costarricense, basado en el abordaje de la dimensión ideológica de los acontecimientos y en el accionar de la ideología como mecanismo dinámico y generativo, que simplifica y esquematiza la realidad, sin admitir posiciones ambiguas y neutras.

La ideología funciona de manera inconsciente; responde a la necesidad que tienen los grupos de representarse a sí mismos y condensa una actitud no crítica, basada en relaciones encubiertas y de disimulo. Por su carácter incongruente y discordante con la realidad, constituye "una racionalización que juega como pantalla respecto de lo real" (Ricoeur 2001: 13-4). No obstante, el escritor como sujeto tiene una capacidad de respuesta frente a ella y en el caso concreto de La calle, jinete y yo, Hernán Elizondo Arce se propone desenmascarar la(s) ideología(s) que actúan en el espacio textual, evidenciando una clara actitud subversiva que se aprecia en el plano de la enunciación con los recursos retóricos que emplea.

Estos recursos son los que posibilitan un enfoque particular de la realidad, no reproduciéndola de forma mecánica, sino aproximándose a ella desde una perspectiva metafórica, irónica, paródica y humorística, como se desprende de la siguiente afirmación de Ramón Luis Acevedo:

\footnotetext{
De un discurso esencialmente mimético que pretendía ser traslado directo del entorno sociopolítico, pasamos a un discurso mucho más libre, irreverente e imaginativo que funciona más bien como metáfora, distorsión o reinvención de lo real para iluminarlo desde ópticas inéditas y representarlo en su problemática complejidad. Se había hecho antes pero ahora se generaliza y se hace con mayor conciencia. La creciente importancia concedida al lenguaje, el tono humorístico, paródico o satírico, la proliferación de voces, la reformulación de la historia, la complejidad estructural, la ausencia de soluciones narrativas fáciles, la problematización de la propia escritura implican también una transformación de los esquemas mentales del lector que necesita para redefinir su concepción del discurso literario (Acevedo 1992:50) ${ }^{3}$.
} 


\section{La trampa en la sonrisa}

El humor, como estrategia narrativa, puede agruparse en tres categorías: la que analiza las formas de incongruencia, la que se refiere a la hostilidad (malicia, superioridad o agresión) y la que asume el humor como una forma de relajación (Zavala 1993:14-5). En el texto literario pueden aparecer las tres categorías, las cuales actúan como disparadores semánticos que obligan al lector a decodificar el discurso y a asignar los significados.

La calle, jinete y yo se propone como un texto que interpela constantemente al lector, gracias a la utilización de un humor que le permite conformar una visión relajada de las relaciones sociales, religiosas, políticas y familiares que se presentan en el espacio narrativo, empleando diversos juegos de palabras y asediando distintos tópicos que se convierten en generadores de humor. El narrador se mofa de las jerarquías que ordenan la sociedad; de ahí que con frecuencia se alude a quienes ostentan el poder y se van descubriendo las contradicciones que encierran. Igualmente, se presenta el humor como un arma de denuncia de la transgresión de las normas para enfatizar el castigo, como le sucedió a Miguel, quien cansado de cuidar a su hermano, un día decidió escaparse y participar del juego "La zorra”, en el que pensaba obtener los mejores resultados del mundo, pero la situación final fue nefasta para él:

\footnotetext{
A los pocos segundos me sentí cansado y tomé el rumbo de la cueva pensando en que me faltaba mucho para ser una buena zorra. No obstante, llegué sin contratiempo a la fila, me puse en cuatro patas y me escurrí entre el mar de piernas de la cueva infernal.

Fue entonces cuando me estremecí. Un chorro de agua caliente me mojaba la espalda y no me costó mucho comprender que había caído en una trampa y que todos los chiquillos me estaban orinando. Los gritos y las risas aumentaban mi tortura y, dando manotazos, me salí del maldito grupo para echar a correr desesperado (p. 25).
}

En otras ocasiones, el humor permite atacar modelos morales y con ello el narrador descubre la falsedad en los personajes, principalmente los de carácter femenino:

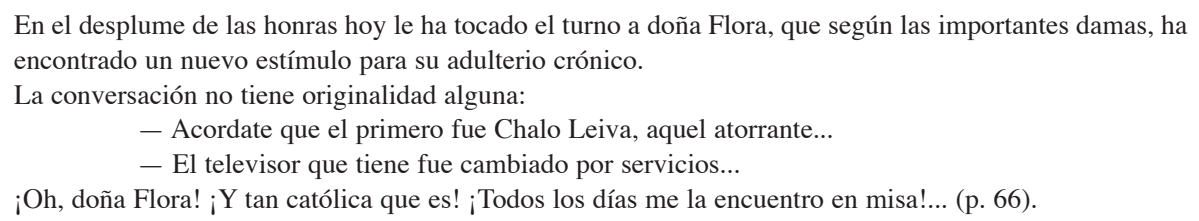

No escapa a este humor el cura, quien debe ser modelo y ejemplo de fe y, sin embargo, es descubierto en una actitud que contradice sus principios, como lo demostró el Gordo Timburil, un remedo de Sherlock Holmes, encargado de revelar todos los amoríos del pueblo. En una ocasión se lo encontró por la calle y al denunciarlo se burla de él, como se nota en este diálogo:

- Padre, anoche lo vi en cierta casa a las dos de la mañana...

- Sí. - Respondió el cura sin inmutarse. - Andaba dándole los últimos consuelos a una enferma.

Y Timburil le respondió, sonriendo picarescamente:

- Me consta que fueron los últimos, porque ya su sacristán le había dado los primeros (p. 64).

De esta manera, el humor se convierte en una forma sutil y relajada para denunciar a aquellas figuras que ocupan una posición importante en la esfera social. En plena sonrisa se 
fragua una actitud desestabilizadora de las jerarquías e, incluso, la crítica se extiende a ciertos personajes que socialmente muestran una cara positiva, pero esta solo constituye una máscara que encubre su falsedad moral.

\section{La ironía como filtro distanciador}

La ironía, como forma del discurso, presenta un sujeto desligado de su situación que asume una distancia ante el mundo narrado (Titler 1990: 17); de ahí que haya sido considerada también como una ingeniosa "defamiliarización", en la que el lector se ve obligado a asumir una actitud de razonamiento frente a los enunciados que exponen la realidad de un modo conflictivo y disimulado (Ballart 1994: 450).

Este recurso opera también en un plano ideológico, pues desnuda aquellos mecanismos que tienden a mostrar una sociedad armónica y afecta de manera radical la dimensión abierta e intransitiva de la obra literaria, pues los planteamientos de denuncia de las ideologías quedan claramente orientados, como se observa en la obra de Elizondo Arce.

Mediante la ironía, se desentraña la falsedad y la corrupción que parecen inherentes a los grupos de poder, principalmente aquellos que basan su autoritarismo en la materialidad de sus recursos:

\footnotetext{
En cierto modo, somos una institución social, Jinete. La sociedad necesita también de los desamparados, de los vagabundos, de la escoria de la calle. Somos una válvula de escape para su generosidad, una especie de parapeto que les sirve para ganar el cielo con limosnas. ¿Entiendes? Nos tiran a los pies las migajas del banquete y enseguida se inclinan ante Dios para decirle: "Gracias porque me has permitido hacer un acto de caridad con este pobre en quien miramos a un hermano. Gracias, mil gracias, oh dios, porque con ello nos hacemos acreedores a la gloria de tu reino" (p. 53).
}

Esta visión irónica y también paródica de la realidad alcanza un grado extremo cuando en las líneas finales de la obra despunta la actitud indiferente y conformista de don Lucas, quien recibe una severa crítica de Antonio. Don Lucas le responde:

\footnotetext{
-Supongamos que sí. Pero, ¿quién lucha por el progreso del mundo que esté limpio de ambición? ¿No se halla la humanidad al borde del colapso precisamente porque se encuentra dividida en dos bandos y cada uno de los dos quiere arreglar el mundo a su manera? ¿Por qué si en verdad lo que buscan es la felicidad del hombre, no ceden en el rencor y se unen ambos en la empresa? No. Decididamente no. Y el resultado de esta pugna va a ser que un día de tantos una masacre espantosa en que se repetirá multiplicado el crimen de Hiroshima. ¿Y qué? ¿Voy a ponerme a llorar, o a gritar o a protestar? ¿Para qué? ¿Me van a escuchar en Pekín, en Washington o en Moscú? No, Antonio. Al diablo con el idealismo. Yo aprendí a conformarme. Y cuando quiero pensar, porque yo también tengo cerebro, porque no he perdido del todo la sensibilidad humana, entonces voy a la cantina, me emborracho, y me hago un mundo ideal para mí solo (p. 106).
}

La ironía se muestra también en la formulación de una crítica severa contra el aparato educativo, representado metafóricamente por los educadores, quienes, cuando deberían ser artífices de alumnos activos que se cuestionan su realidad, solo se convierten en reproductores de los mitos y discursos que han articulado una falsa conciencia sobre la realidad nacional; o bien, la ironía aparece encubierta para denunciar a los empleados públicos que utilizan los recursos del estado para fines personales de carácter político y para desnudar las características nefastas del pueblo, como aparecen en boca de Judas: "Te dejo, pueblo sin mengua,/donde hay tanto criminal,/que nunca mata a puñal/pero mata con la lengua" (p. 77). 
La ironía se constituye, asimismo, en un recurso para mostrar desde una perspectiva conceptual la falsedad en que se desenvuelve el pueblo y la impotencia que siente el narrador al pretender cambiar el mundo, pero no encuentra el espacio posible, pues la pureza y la justicia se han convertido en utopías. De esta manera, la novela nos actualiza la conocida frase de la esposa del protagonista de El coronel no tiene quien le escriba, quien de una manera sincrética y condensada manifiesta "El mundo está corrompido" (García Márquez 1978: 24).

Junto a la presentación irónica de la corrupción en los niveles más concretos de la realidad social, y azotando los diferentes estrados de la sociedad, especialmente aquellos erigidos como modelos, la ironía alcanza una connotación superior y se convierte en una voz que pretende crear conciencia sobre el avance de la sociedad y sobre el comportamiento humano. No solo se ataca al maestro, al político, al sacerdote, al empleado público, a la mujer, al pueblo entero, sino que se genera una connotación mayor donde se plantean las incomprensibles contradicciones de la época actual, una época en la que el hombre se ha sentido orgulloso de los múltiples avances tecnológicos y de haber superado la barbarie histórica y el instinto primitivo. No obstante, según el narrador, la humanidad no ha avanzado ni un milímetro, pues hoy, en la llamada cumbre de la civilización y de la cultura, dispone de las más sofisticadas estrategias de asesinar y matar, mucho más que en el pasado (p. 10).

\section{La construcción del icono de un pueblo mediocre y conformista}

Elizondo Arce en su novela edifica el icono de Costa Rica como pueblo mediocre, donde todos sus habitantes carecen de proyectos definidos que orienten el desarrollo del país. Las clases dominantes y las jerarquías del poder actúan arbitrariamente, de modo que solamente velan por sus intereses, mientras que el pueblo, sumido en una atmósfera de pereza y astenia, carece de una definición clara para su progreso. Incluso, contaminado por una visión existencial de la vida, mostrada en repetidas ocasiones por el protagonista, entra en el desorden y la desidia que lo desactiva de manera radical. Así, la sombra, la mediocridad y el sueño se constituyen en la fuerza actancial más clara que lo caracteriza:

\footnotetext{
La tarde deja un fulgor crucificado en las esquinas y a lo largo de la calle rompen las primeras sombras las campanadas del Angelus. La gente empieza a desperezarse un poco, a asomarse a la vida exterior que se va animando en gestos repetidos y desordenados, dentro de la monotonía de este pueblo mediocre y soñoliento (p. 55).
}

Hernán Elizondo, desdoblado en aquel "pobre diablo", aún hoy sigue manteniendo una actitud subversiva y de denuncia contra la farsa de quienes abusan del poder o simplemente corrompen nuestra sociedad, como son elocuentes las palabras del narrador en el texto breve "Retorno del pobre diablo":

He dormido una siesta de treinta años. Y ahora despierto, así como de pronto, me dan ganas de gritar mis verdades de siempre, de denunciar ante los cielos sordos las injusticias de siempre, de maldecir con los pulmones rotos a los indeseables de siempre (Elizondo Arce 2002: 65).

La calle, jinete y yo marca una importante ruptura en relación con aquella narrativa costarricense que se había caracterizado por la ficcionalización del espacio rural y folclórico, 
pues continúa la línea trazada por Yolanda Oreamuno al novelar el espacio urbano y la problemática que de él se deriva, incorporando una pluralidad de voces y presentando una concepción relativa de la realidad, así como aportando en la construcción del personaje novelesco, que es perfilado de una manera ambigua y contradictoria. En esta dirección, la novela de Elizondo Arce evoluciona en forma paralela a la novela hispanoamericana, ya que presenta rasgos claves de la revolución que experimentó esta en la década de los setentas.

La obra recoge y perfila la atmósfera urbana como espacio que se desmorona producto del comportamiento hipócrita y corrupto de los representantes del poder; y sin plantear los problemas derivados de las aglomeraciones y la explosión demográfica, selecciona la calle como elemento simbólico que anuncia la farsa y el carnaval en el que se desenvuelven los hombres de la ciudad, incompletos y ambiguos. De ahí que la obra propone un rechazo directo a las formas de vida citadinas y enfatiza la necesidad de un cambio radical basado en pilares como la justicia y la solidaridad, sin dejar de traslucir un desencanto, como lo testimonia Don Ramiro con sus palabras:

\footnotetext{
Era claro y tangible, era que sus sesenta años de idealismo habían hecho de él un Diógenes violento y cáustico, que no se daba el trabajo de buscar a un hombre puro porque ya llevaba en sí mismo la convicción de no encontrarlo.

Él lo decía:

“QQuerés hallar a un hombre justo? Buscadlo donde no llegue el oleaje de ese mundo turbulento, en el que se revuelcan los rebaños vendidos, engañados, sí, pero siempre rebaños. Buscadlo allí donde no llegue el brazo de los inquisidores, el puño de los demagogos o el sermón de los farsantes" (p. 93).
}

El autor, sin prescindir de interrogarse por los problemas sociales, históricos y políticos de la sociedad costarricense, crea un texto en el que se sumerge en ambientes psicológicos e intimistas, revoluciona las estructuras del lenguaje y del discurso literario y asume una posición epistemológica ante la realidad, lo que le posibilita superar los criterios racionales y objetivos que habían definido la narrativa realista de los años anteriores.

\section{Notas}

1. Arturo Arias plantea esta afirmación con un carácter general referido a toda la novela centroamericana del periodo.

2. Véase: Elizondo Arce, Hernán. 1981. La calle, jinete y yo. San José, Costa Rica, Editorial Costa Rica, p. 52. En las siguientes citas de esta obra solo se indica el número de página entre paréntesis. Los demás datos corresponden a esta edición.

3. Este crítico coincide con las planteamientos de Arturo Arias, especialmente en cuanto a la superación de un discurso mimético, con lo cual los novelistas crean obras más complejas en su dimensión estética.

\section{Bibliografía}

Acevedo, Ramón Luis. 1992. "Rumbos de la narrativa centroamericana actual”. Revista Káñina. XVI (2): 39-51.

Arias, Arturo. 1990. “Nueva narrativa centroamericana”. Centroamericana. Núm. 1: pp. 9- 23. 
Ballart, Pere. 1994. Eironeia. La figuración irónica en el discurso literario moderno. Barcelona: Quaderns Crema.

Elizondo Arce, Hernán. 1971. La ciudad y la sombra. San José: Lehmann.

1981. La calle, jinete y yo. San José: Editorial Costa Rica.

2002. Anécdotas y relatos. San José: Editorial Guayacán.

García Márquez, Gabriel. 1978. El coronel no tiene quien le escriba. México: Biblioteca Era.

Noguerol, Francisca. 1995. La trampa en la sonrisa. Sátira en la narrativa de Augusto Monterroso. Sevilla: Universidad de Sevilla.

Ricoeur, Paul. 2001. Del texto a la acción. México: Fondo de Cultura Económica.

Sáinz de Medrano, Luis. 1989. Historia de la literatura latinoamericana (Desde el modernismo). Madrid: Taurus.

Titler, Jonathan. 1990. Ironía narrativa en la novela hispanoamericana contemporánea. Traducción Carmen Bravo. Colombia: Banco de la República.

Zavala, Lauro. 1993. Humor, ironía y lectura. México: Universidad Autónoma Metropolitana. 